\title{
Psicanálise e Acompanhamento Terapêutico: Quando a Cidade se Torna o
}

\author{
Setting Analítico da Psicose
}

\author{
Mariana Vieira Morais* \\ Universidade Federal de São João del-Rei - UFSJ, São João del-Rei, MG, Brasil \\ ORCID: https://orcid.org/0000-0002-4239-9035 \\ Fuad Kyrillos Neto** \\ Universidade Federal de São João del-Rei - UFSJ, São João del-Rei, MG, Brasil \\ ORCID: https://orcid.org/0000-0001-8071-0907
}

\section{RESUMO}

O Acompanhamento Terapêutico (AT) nasce no contexto da Reforma Psiquiátrica e, embora não figure na legislação como uma política pública oficial, integra-se a diversos serviços voltados para a saúde mental. O AT, que traz como característica dominante o deslocamento físico em espaços públicos e o setting móvel, vem ganhando cada vez mais protagonismo nos serviços que estão se constituindo no processo reformista brasileiro. Partindo de uma fundamentação psicanalítica a respeito da psicose, discutimos um aspecto que nem sempre vem em primeiro lugar nas teorizações produzidas a respeito do AT: sua dimensão clínica. Para isso, valemo-nos do método da psicanálise aplicada, pois este permite o estudo psicanalítico de fenômenos sociais, que estão além do setting clínico tradicional. Concluímos que o AT é um espaço para fazer a escuta subjetiva tão necessária à psicose, sem deixar de lado os aspectos políticos e sociais atrelados à loucura.

Palavras-chave: acompanhamento terapêutico, clínica da psicose, psicanálise.

\section{Psychoanalysis and Therapeutic Accompaniment: The City as Analytical}

\section{Setting of Psychosis}

\begin{abstract}
The Therapeutic Accompaniment (TA) rises in the context of the Psychiatric Reform and, although it does not fit into legislation as an official public policy, it ends up entering several services aimed at mental health. The TA, which has as dominant key the movement in public objects and the moving setting, has been gaining more and more prominence in the services that are being constituted in the Brazilian reform process. We discuss, from the psychoanalytic background about psychosis, an aspect that does not always come first in the theorizations produced about the TA: its clinical dimension. For this, we use the method of applied psychoanalysis, which allows the psychoanalytic study of social phenomena that are beyond the traditional clinical setting. We conclude that TA is a space of privilege to make
\end{abstract}

ISSN $1808-4281$ 
the subjective listening that is so necessary to psychosis, without leaving aside the political and social aspects that are attached to madness.

Keywords: therapeutic accompaniment, psychosis clinic, psychoanalysis.

\title{
Psicoanálisis y Acompañamiento Terapéutico: La Ciudad se Convierte en el
}

\section{Setting Analítico de la Psicosis}

\begin{abstract}
RESUMEN
El Acompañamiento Terapéutico (AT) nació en el contexto de la Reforma Psiquiátrica y, aunque no se configura en la legislación como una política pública oficial, adentra diversos servicios dirigidos a la salud mental. El AT, que trae como característica dominante la marcha en espacios públicos y el setting móvil, viene ganando cada vez más protagonismo en esos servicios que se están constituyendo en el proceso reformista brasileño. Discutimos, a partir del fundamento psicoanalítico acerca de la psicosis, un aspecto que no siempre viene en primer lugar en las teorizaciones producidas con respecto al AT: su dimensión clínica. Para ello, nos valemos del método del psicoanálisis aplicado, que permite el estudio psicoanalítico de fenómenos sociales, los cuales están más allá del setting clínico tradicional. Concluimos que el AT es un espacio de privilegio para hacer la escucha subjetiva tan necesaria a la psicosis sin dejar de lado los aspectos políticos y sociales que están ligados a la locura.
\end{abstract}

Palabras clave: acompañamiento terapéutico, clínica de la psicosis, psicoanálisis.

A loucura é um tema que precede o momento em que vivemos, mas a questão vem se traduzindo na atualidade e ganhando novos arranjos. Um dos maiores marcos ligados ao tratamento da loucura é a Reforma Psiquiátrica, que abre caminho para serviços e abordagens que tratam do sujeito e se distanciam do foco na doença. Existem diversos desdobramentos dos serviços que substituem o modelo manicomial, um deles é a prática conhecida como Acompanhamento Terapêutico (AT), um dispositivo que se configura no ambiente imediato dos acompanhados-e passa por suas relações sociais.

O AT nasce com o objetivo de dar uma nova forma de assistência à loucura para além dos muros institucionais. Assim, sua principal característica é o setting móvel, especificidade que permite que o tratamento seja realizado à medida que acompanhado e acompanhante se deslocam por locais públicos. O AT não é restrito ao campo da loucura, no entanto nasce nesse contexto e é nele que, ainda hoje, continua verificando-se sua principal aplicação. 
Atualmente é usado como estratégia de alguns serviços para assistir a pessoas-que, por diversas razões, estão em condições avessas ao tratamento em um setting tradicional. É interessante ressaltar, ainda, que o trabalho não é restrito ao campo psi, podendo ser praticado por diversas disciplinas, como Enfermagem, Medicina e Educação Física entre outros. Porém, pela forma como vem se organizando e também por ser uma estratégia para evitação de internações, está cada vez mais dispondo do protagonismo de profissionais da saúde mental e, consequentemente, ganhando com eles novos enfoques teóricos que subsidiam sua prática. Interessa-nos, em nossa proposta, este AT que é principalmente guiado por acompanhantes que estão, de alguma forma, nesses serviços públicos e que fazem uso desse trabalho em suas intervenções.

O AT, inspirado nos princípios da Reforma Psiquiátrica, promove um novo espaço ao próprio acompanhamento da loucura: a saída dos asilos para ocupação dos locais públicos. Nesse contexto, é de grande importância, como nos aponta Palombini (2006), que o processo de desinstitucionalização da Reforma coloque em jogo a desinstitucionalização da própria clínica.

O AT não é necessariamente um trabalho clínico. Na verdade, esse aspecto sequer é levado em consideração nas muitas histórias que se contam sobre esse dispositivo. Em contrapartida a isso, nosso trabalho se apoia na defesa de uma clínica em movimento para o AT como possibilidade de construção e articulação aos ideais de inclusão social da Reforma e com uma escuta subjetiva que é tão necessária a esse sujeito incomum da loucura - uma escuta no local de ocupação cotidiana desse sujeito.

Fantin (2017) revela que o AT dentro do campo da Saúde Mental, apesar de não figurar oficialmente como uma política pública, tem um importante papel na consolidação da Reforma Psiquiátrica brasileira, pois oferece uma possibilidade de tratamento aos pacientes que subverte os protocolos terapêuticos existentes na rede de saúde. Tentamos, então, pensar num dispositivo que possa resgatar a cidadania dos sujeitos, propondo que o AT viabilize também - e isso é indispensável ao nosso trabalho - uma atenção singularizada à psicose, podendo assim ser uma forma de contribuir com esse processo reformista ainda em construção. Essa clínica que estamos propondo para o AT parte de algumas construções psicanalíticas a respeito dessa forma tão única que o sujeito da psicose tem de se colocar perante a linguagem.

No que concerne ao método utilizado neste trabalho, o princípio de desinstitucionalização da clínica (Palombini, 2006) nos remete ao que Lacan (1967/2003) nomeia como "psicanálise em extensão", a fim de falar das aplicações da psicanálise no 
mundo e de sua presentificação na sociedade. Ele parte do pressuposto que a psicanálise possui um compromisso político com as questões de seu tempo, sendo necessárias a adaptação e a constante transformação desse método para cumprir tal missão. Assim, para pesquisar um objeto que está presente fora do contexto clínico tradicional - no qual é necessário acompanhar suas implicações históricas e sociais como o AT - usamos o método que Rosa (2004) nomeia como psicanálise aplicada. Essa perspectiva metodológica exige a colocação do psicanalista no lugar de analisante, atrelado a uma implicação com seu objeto, o que o faz interrogar eticamente sobre as formações de estranhamento com o qual se encontra (Dunker, 2013). Desse modo, a psicanálise aplicada, ou extramuros, circunscreve o método psicanalítico a fenômenos sociais que estão além do setting clínico tradicional. Isto é o que guia nosso trabalho.

Tomaremos o AT como um fenômeno social que vem passando por diversas transformações no desenvolvimento de sua prática para chegar, desta forma, a uma possibilidade de um AT orientado pela perspectiva psicanalítica. É imprescindível ressaltar que o AT é um fenômeno em movimento e contempla, ainda, novas construções a respeito de teorias que o embasem. Nossa aposta na psicanálise aplicada se dá por acreditarmos que ela permite fazer uma amarração entre as questões sociais presentes na democracia e o sujeito que nela se insere. Podemos pensar, então, a partir da psicanálise aplicada, em uma dimensão clínica e também social quando discutimos as andanças desses sujeitos do AT na rede pública de saúde.

\section{Acompanhamento Terapêutico e Reforma Psiquiátrica}

O AT teve origem na Argentina na década de 1970, apresentando-se como um atendimento de abordagem múltipla, inicialmente voltado para pacientes psicóticos e dependentes químicos. Enquanto campo de atuação reconhecido, surgiu em Buenos Aires, no Centro de Estudos e Tratamento de Abordagem Múltipla (CETAMP), uma Comunidade Terapêutica de ascendência psicanalítica. Organizada sob influência das Comunidades Terapêuticas inglesas, contava com um grupo formado por diversos profissionais. Dessa maneira, naquele momento, o acompanhante terapêutico aparecia como mais um dos membros da equipe multiprofissional. O trabalho feito tanto dentro quanto fora das instituições-era realizado sem vinculação com hospitais psiquiátricos, mas em associação com clínicas e Comunidades Terapêuticas (Reis Neto, Oliveira, \& Pinto, 2011). 
A prática do AT chega ao Brasil no final dos anos 1970, sob influência direta da Argentina. A forma como os serviços de saúde vinham se organizando no país, fruto de diversos movimentos históricos (como a Declaração de Caracas e a $1^{\mathrm{a}}$ Conferência Nacional de Saúde Mental), abriu espaço para uma articulação com o AT. Deixando de se preocupar com a doença e com seu foco puramente prescritivo, a atenção psicossocial, projeto de grande importância no que se refere à reestruturação dos serviços de saúde mental, passou a entender a necessidade de novos dispositivos, os quais estariam em consenso com o processo de Reforma Psiquiátrica em andamento (Furegato \& Pitiá, 2009).

O AT é um dispositivo terapêutico que possui como característica substancial a andança e a ocupação de espaços extrainstitucionais. Ao reduzir barreiras sociais e subjetivas nas suas andanças, permite ressignificar a forma de pertencimento a esses espaços. O AT, $a$ priori, não conta com um espaço definido para a sua realização, podendo passar por diversos lugares sem se fixar a eles (Reis Neto et al., 2011).

Santos, Motta e Dutra (2005) esclarecem que o AT não é uma profissão em si, mas sim uma modalidade de tratamento existente dentro do campo da Saúde Mental. O dispositivo, movido pelo ideal de desospitalização e reinserção política do psicótico, apresenta-se, principalmente, como um recurso da Reforma Psiquiátrica e pode estar ligado a serviços substitutivos, visando à inclusão do sujeito no tecido social para que ele se reconheça em seu lugar de cidadão.

O trabalho traz a marca de uma prática terapêutica interdisciplinar, podendo receber contribuições epistemológicas e teóricas de diversos campos: Psicologia, Filosofia, Antropologia, Medicina, Sociologia, Enfermagem e Geografia, entre outros. Assim, esse dispositivo, que não conta com uma técnica predefinida para sua prática, pode integrar projetos existentes em um vasto campo de ações, como intervenções clínicas, serviços substitutivos, trabalhos familiares, pessoas em conflito com a lei, casas de passagem, escolas, asilos, etc. (Silva \& Silva, 2006). Apesar de existirem inúmeras possibilidades no campo do AT, fazemos aqui o recorte que nos interessa neste trabalho: um dispositivo voltado para a atuação no campo da loucura - campo no qual nasce o AT e em que, ainda hoje, continua tendo sua maior aplicabilidade.

Marco e Calais (2012) ressaltam que, embora haja diferentes pessoas falando sobre AT em diversas perspectivas, há um consenso na literatura de que essa atividade se sustenta em um tripé: atendimento fora do consultório, diálogo com a família e trabalho em equipe. A aposta em estar com o sujeito em locais públicos, na perspectiva de Dimenstein e Gruska (2015), orienta-se pela tentativa de emancipação, tentando ligá-lo a pontos essenciais de seu 
contexto imediato que ficaram excluídos devido à sua história. Além da integração comunitária, é previsto o empoderamento político e social dos acompanhados por meio da reinserção social.

O acompanhamento deve ser um serviço que evidencia o sujeito, fazendo-o sair da plateia a fim de tomar uma posição mais ativa frente a sua própria história. Para Carrozzo (1991), é comum que o psicótico seja falado por sua família ou pelo social, que, por sua vez, já estabelecem para ele um lugar definido. Cabe, então, um trabalho no sentido de torná-lo um sujeito mais ativo, capaz de responder por si mesmo. O AT, pela própria forma como se constitui o trabalho, permite a utilização de diversos recursos: do paciente, da rua e os do profissional. O paciente pode, dessa maneira, fazer uso de fatos, lugares e cenas que vão surgindo e sendo incorporados ao processo terapêutico. Esses são, antes de mais nada, recursos que podem trazer uma organização, um movimento rumo à estabilização (Caiaffa, 1991).

Palombini (2006) situa o AT como uma prática privilegiada por permitir uma forma de aproximação extremamente rica e significativa aos acompanhados que, por diversas razões, podem se mostrar inacessíveis ou pouco disponíveis para os modelos tradicionais de tratamento. É comum, por exemplo, mesmo em serviços abertos como os Centro de Atenção Psicossocial (CAPS), que os dispositivos utilizados, tais como as oficinas, não abarquem todos ali presentes ao não atenderem à singularidade de cada um. Propomos uma perspectiva de AT orientada pela clínica e que, consequentemente, encontre em seu caminho atividades que fazem parte do desejo dos acompanhados.

Inicialmente, o AT era, na maioria das vezes, requisitado por psiquiatras como uma estratégia de substituição às internações. Era comum, nesse contexto, as equipes de AT fazerem revezamento noite e dia para fornecer um atendimento por 24 horas. Quando a crise cessava, o acompanhamento era diminuído progressivamente até ser interrompido de vez. Logo, o acompanhamento, naquela época ainda chamado de auxiliar psiquiátrico ou amigo qualificado, também poderia ser um recurso usado para medicar e vigiar, pois àquele que solicitava o trabalho "pouco interessava sobre o que o AT conversaria com o sujeito durante o período em que estivessem juntos, desde que tais objetivos fossem cumpridos" (Reis Neto et al., 2011, p. 36-37).

Com o passar do tempo o trabalho começou a ser realizado com cargas horárias menores, pois houve uma mudança na perspectiva de que ele deveria ser feito apenas em momentos de crise ou para evitar internações. Evitar este tipo de situação, a da internação, é um aspecto significativo, mas não se constitui como finalidade única do trabalho. Quando o 
AT se configura na especificidade de um trabalho contínuo, não restrito a momentos de crise, e passa a ocupar os lugares públicos, é permitido que o sujeito elabore uma construção para dar conta dos fenômenos que o tomam de forma invasiva (Reis Neto et al., 2011). Partimos aqui da perspectiva de que o papel do acompanhante passa por um deslocamento quando ele ocupa o lugar de alguém que oferece uma escuta para que o sujeito psicótico possa se estruturar e encontrar modos próprios de significação.

Neste trabalho, interessa-nos levantar a questão que, devido ao fato de o AT ser um campo de atuação muito amplo e passar por diversas configurações ao longo do tempo, a ausência de uma delimitação mais precisa no que se refere ao seu embasamento teórico ainda se faz presente e pode cair, muitas vezes, numa separação entre a dimensão social e o aspecto clínico do trabalho - dicotomia que está presente nos próprios serviços substitutivos que vêm se concretizando como fruto da Reforma Psiquiátrica. Ribeiro (2009) demonstra que, no CAPS, por exemplo, a clínica precisa, por vezes, ceder espaço para intervenções que foquem na sociabilidade. Esta perspectiva que trabalha a reabilitação social de maneira afastada da clínica, proposta claramente influenciada pelos ideais da Psiquiatria Democrática italiana, prioriza o poder de troca do sujeito com seu meio social, buscando atribuir um lugar para além da exclusão do louco.

É óbvio que o movimento de empoderamento político desses sujeitos é de extrema importância para a loucura, porém tais práticas, por vezes, podem se valer de um discurso universalista que, apesar de sua tentativa, nunca conseguirá alcançar todos em suas particularidades. Esta aposta, o imperativo da inclusão, como nomeiam Dunker e Kyrillos Neto (2015), pode levar à cronificação dos sujeitos nos serviços. Dessa maneira, percebemos que existe um grande problema quando a loucura conquista seus direitos políticos e sociais, uma vez que a escuta clínica de sua singularidade é deixada de lado.

Resgatamos, então, em nosso trabalho, o AT como um dispositivo que é fruto da história da Reforma Psiquiátrica e, consequentemente, dessa ideologia, cuja proposta se dá numa separação entre a prática clínica e a dimensão social dos serviços que vêm surgindo. Assim, propomos uma clínica para o AT que acreditamos ser incontornável para a psicose, pois entendemos que falar de direitos políticos e sociais só faz sentido quando abordamos também a questão de uma estabilização ou de uma amarração própria desses sujeitos com o propósito de que possam dar conta de seu sofrimento.

Basaglia (1985), ao falar das instituições da violência - aquelas onde sempre haverá uma relação de violência e dominação daqueles que possuem poder em relação aos que não o têm, argumenta que, mesmo nos novos arranjos, os profissionais (psiquiatra, psicólogo, 
assistente social, etc.) continuarão a exercer algumas formas de violência devido à própria posição de poder que ocupam. Essas atualizações das formas de violência podem vir encobertas pelo discurso científico. Quando o ato terapêutico coincide com esses arranjos, não há, segundo Basaglia (1985), outra solução possível "senão refutar o ato terapêutico, cujo único objetivo é atenuar as relações do excluído com o excludente" (p. 103). Nesse sentido, defende que o próprio ato terapêutico seria uma nova forma de violência, pois, além da relação hierárquica previamente existente entre profissional e atendido, ao tentar reabsorver a crise - que pode ser uma forma de denúncia à situação vivida ou mesmo estabilizá-la -, existe a volta a um estado anterior, uma regressão perante aquilo que era denunciado. Essa negação do ato terapêutico proposta por Basaglia (1985) ainda se faz presente nos serviços de saúde que, atuando no modelo da psiquiatria democrática, fazem valer a premissa de que a cura se dá exclusivamente pela inserção social dos usuários.

Como pensar, então, um dispositivo que possa estar presente nos serviços públicos de saúde e seja capaz de contemplar estas duas dimensões, clínica e política, da Reforma Psiquiátrica ainda em construção? É interessante que a ideia de uma clínica restrita ao setting tradicional, embora tenha seu valor, foi ultrapassada enquanto única possibilidade de oferecer uma escuta. Por isso, o AT é aqui colocado como uma possibilidade de diálogo entre esses pontos, os quais ainda carecem de discussão no processo de renovação da assistência que serviços que vêm se concretizando no Brasil como fruto da Reforma Psiquiátrica prestam à loucura. Ressaltamos, ainda, a importância dessa modalidade de trabalho nos dias atuais, uma vez que o AT, devido à ideia do setting móvel, trabalha com a perspectiva da territorialização dos sujeitos para que o tratamento seja oferecido ali onde estabelecem suas relações mais imediatas - aposta que, infelizmente, vem sendo prejudicada pelas novas políticas que estão surgindo no campo da Saúde Mental ${ }^{1}$.

Um dos conceitos-chave trabalhados no AT é a ideia de Rede Terapêutica. Essa Rede seria tudo aquilo com que acompanhado e acompanhante se deparam em suas andanças, podendo admitir elementos da vida de ambos. Esses elementos que vão surgindo na cena são essenciais, pois são justamente eles que permitem que o sujeito crie vínculos e possibilidades para além da equipe multiprofissional do serviço ao qual está vinculado e até mesmo de seu próprio acompanhante (Nogueira, 2009). Acreditamos que essa rede só se constrói e que a cronificação no serviço ou mesmo na pessoa do acompanhante só pode ser afastada, se fazemos a escuta das questões desse sujeito - escuta que, neste trabalho, propomos guiar pela lente de uma clínica psicanalítica das psicoses. Nossa pesquisa, ao apostar nesta perspectiva de clínica como uma possibilidade de orientar o trabalho do acompanhante terapêutico, 
pretende contribuir com sua prática, fazendo com que essa clínica do acompanhamento terapêutico se faça a partir de um balizamento teórico estabelecido.

\section{O Percurso de uma Psicanálise Aplicada no Acompanhamento Terapêutico}

Apostamos que a psicanálise, no seu arcabouço teórico a respeito de uma clínica da psicose, possa ser uma fundamentação e uma nova forma de responder as questões que surjam durante a prática do AT. É indispensável, nesse contexto, um manejo clínico para a psicose que possa guiar a prática do acompanhante terapêutico, fazendo-o se distanciar de uma atuação que não faz mais que repetir, agora em espaços extrainstitucionais, discursos normativos que podem ser tão invasivos para a psicose.

Não é possível que haja reforma psiquiátrica sem a escuta clínica necessária do sujeito que está presente na psicose (Castro, 2012; Quinet, 2006b). Para se distanciar da ideia de conduzir o sujeito a aspirações educativas ou incluí-lo no mundo social por meio de alguns trabalhos, no sentido de uma aproximação do comum, cabe, no tratamento psicanalítico da psicose, "a necessidade do agente de escuta do sujeito incomum" (Castro, 2012, p. 145). Isso porque mesmo fazendo uso de uma língua comum a todos, o sujeito psicótico pode, por vezes, ser mais falado por ela do que se servir da língua. Quando há a pretensão de aproximar esse sujeito do comum, da norma, do que não é delirante ou estranho, ao invés de falar de si, podese engendrar um resultado desastroso - o de que ele se cale.

A psicose sempre foi uma questão muito emblemática para a psicanálise. Freud (1905/1996), embora mantivesse um interesse teórico pela psicose, considerava que esta não era acessível à psicanálise, chegando inclusive a contraindicar uma prática de tratamento para essa condição. Tal é o afastamento do autor em relação a um tratamento para a psicose que sua mais importante obra a respeito do tema, O caso Schreber (Freud, 1911/2010), deu-se a partir da análise da memória autobiográfica escrita por um juiz de Direito que passou por uma internação de longos anos. Nessa obra, Freud resgata a trama criada por Schreber quando constrói sua produção delirante pela escrita até que consiga, por meio dela, uma estabilização de sua condição. Assim, ele reconstrói a ordem de seu mundo por meio do delírio. Esta forma de trabalho - a produção delirante - não é um sintoma da doença que deva ser extirpado, como se considera na Psiquiatria, mas sim uma tentativa de cura e, portanto, deve ser sustentado.

Um ponto crucial dessa obra é que Freud (1911/2010), ao fazer a análise do delírio das memórias de Schreber, argumenta que o psicótico consegue revelar, embora de maneira 
distorcida, aquilo que na neurose é posto em segredo pela condição do recalque. Nesse momento, ele ainda não trabalha outra forma de defesa para a psicose que não o mecanismo do recalque que vinha desenvolvendo na clínica das neuroses. Em As Neuropsicoses de Defesa, Freud (1894/1996) marca a conexão entre neurose e psicose como produtos de mecanismos de defesa. Apesar de, nesse momento, o autor ainda não fazer uma diferenciação substancial entre as duas, situa a defesa na neurose como uma representação que foi isolada de seu afeto, que, por sua vez, permanece livre para encontrar outros destinos, como criar sintomas histéricos ou se ligar a representações obsessivas. Já a defesa na psicose é marcada como mais poderosa e eficaz, pois a representação incompatível é rejeitada pelo Eu juntamente com seu afeto, comportando-se como se nunca tivesse existido (Freud, 1894/1996).

Mesmo que em um primeiro momento essas formas de adoecimento sejam colocadas como resultado do mecanismo de defesa do recalque, é aquilo que distingue as variações dessa defesa, para Simanke (1994), que contribuiria para que Freud estabelecesse a distinção entre neurose e psicose. É somente em sua segunda tópica, com a proposta da divisão do aparelho psíquico em Eu, Supereu e Isso, no qual o Eu perde o posto de senhor em sua própria casa, que Freud (1917/2010) iria pensar de maneira determinante uma distinção entre os termos neurose e psicose.

Na neurose, de acordo com Freud (1923/2011), o Eu se defende de uma satisfação pulsional pretendida pelo Isso, para que possa se submeter à realidade. Essa defesa se dá por meio do mecanismo do recalque, já que o sujeito precisa contestar o objeto no qual a pulsão quer se realizar. Aquilo que foi recalcado volta, então, sob a forma de sintomas neuróticos. Se na neurose o conflito está entre o Eu e o Isso, na psicose esse conflito ocorre entre o Eu e o mundo externo. Nessa condição, o mundo é edificado em conformidade com os desejos do Isso e o motivo da ruptura com o mundo externo está na frustração do desejo imposta pela realidade. Assim, de forma diferente da neurose, que restringe somente uma parte da realidade, na psicose ocorre uma rejeição mais radical, uma vez que ela deixa de sofrer investimentos.

Foi em 1924, no artigo Neurose e psicose, que Freud situou a psicose como uma proposta de categoria nosográfica própria de sua obra. A modalidade do recalque como única forma de defesa sofre uma desconfiança e surge uma nova questão: qual mecanismo pode estar presente na origem da psicose de forma que equivalha ao papel que o recalque tem para a neurose? A partir daí a modalidade de defesa do recalque é abandonada no que se refere à 
psicose e o mecanismo passa, então, a ser definido como rejeição (Verwerfung) (Freud, 1924/2011a).

Vimos, então, que Freud desenvolve, ao longo de sua obra, uma concepção de psicose baseada nos conceitos e acúmulos de conhecimento das elaborações que possuía no momento de sua teorização. $\mathrm{O}$ autor supera a ideia de recalque, característica que traz da clínica das neuroses, e alcança uma especificidade de defesa própria para a psicose: a rejeição (Verwerfung). Porém, esta proposta de um mecanismo de defesa para a psicose-que seja análogo ao que o recalque oferece para a neurose acaba não possuindo um fechamento definitivo em Freud, sendo esse tema retomado posteriormente por alguns autores. Lacan, que se apropria de elementos da teoria freudiana para falar sobre o tema da psicose, trabalha essa questão. O autor faz uso dessas ideias de defesa trabalhadas por Freud e, mantendo a dissimetria estrutural existente entre neurose e psicose, acrescenta algumas elaborações próprias, construídas a partir de suas experiências.

Existe a proposta, por parte de Lacan, que a psicanálise possa contar com uma psicopatologia própria, para além daquelas descritas pela Medicina e pela Psiquiatria. Nesse sentido, para Dunker (2010), quando se fala de uma clínica de orientação lacaniana existe também um diagnóstico - um diagnóstico psicanalítico - situado não como uma doença orgânica ou um desvio, mas sim pela forma como o sujeito se coloca perante o outro e pela sua relação com a linguagem. Dessa maneira, Lacan desenvolveu uma clínica estrutural na qual esse diagnóstico passa a ser totalmente congruente com a lógica de intervenção ao longo do tratamento e de acordo com a ética própria à psicanálise.

Lacan (1955-1956/1988) parte da tentativa de fazer uma explanação sobre a dimensão clínica e nosográfica que cerca a temática da psicose para chegar, então, ao que indica como objetivo principal desse seminário: seu tratamento. Tentando resgatar o que seria a psicose no campo psiquiátrico, ele acaba se afastando da ideia de demência e a situa, assim como faz Freud, no campo das loucuras. Nesse seminário, o inconsciente é apresentado como uma linguagem, e Lacan retoma as duas formas de defesa tratadas por Freud: o recalque e a Verwerfung. O recalque, conceito clássico trabalhado pela psicanálise, está sempre operando, assim como seu avesso, que faz o retorno no campo simbólico por meio de sintomas e outros fenômenos que sempre dão prova de sua existência. Todavia, a outra forma de defesa, a Verwerfung, é de outra ordem e possui um modo um tanto quanto diferente de irrupção, pois nela o que é recusado no simbólico faz seu reaparecimento no real.

Diferentemente da neurose, na qual a simbolização é articulada dando origem ao recalque, ocorre na psicose uma etapa em que a simbolização se faz de forma diferenciada. $\mathrm{Na}$ 
psicose, para Lacan, ao invés do recalque como forma de defesa, existe uma rejeição, uma vez que algo primordial no sujeito escapa à simbolização. Assim, quando propõe que o que é rejeitado no simbólico faz o retorno pelo real é porque "na relação do sujeito com o símbolo, há a possibilidade de uma Verwerfug primitiva, ou seja, que alguma coisa não seja simbolizada, que vai se manifestar no real” (Lacan, 1955-1956/1988, p. 98).

É interessante notar na proposta lacaniana que o que falta ao sujeito, essa capacidade para a simbolização, é o que o estrutura, pois aquilo que se submete a uma foraclusão (Verwerfung) e não à simbolização (Bejahung) primitiva, gera efeitos no modo como ele se colocará na linguagem. Dessa maneira, para Lacan, só se pode estabelecer um diagnóstico de psicose sobre a observação de que existe no sujeito um distúrbio na ordem da linguagem.

Para entendermos o papel da peculiaridade de simbolização que leva à psicose, temos que voltar a um conceito chave que Lacan resgata de Freud, embora não muito desenvolvido por esse autor, mas que é decisivo em sua teorização: a Verwerfung. Quinet (2006a) nos conta que Lacan propõe a tradução do termo Verwerfung, adotado por Freud, como foraclusão, tomando-o emprestado do vocabulário jurídico devido à proximidade com a forma de defesa que diz existir na psicose. Na linguagem jurídica, o termo faz referência a um direito ou faculdade perdidos pela não apresentação do recurso no prazo adequado e sem que haja a possibilidade de recorrer. Fazendo uma analogia dessa lógica com o tema da psicose, Lacan diz que o sujeito psicótico foi incluído fora da lei simbólica e terá que construir suas relações a partir disso, pois a possibilidade de simbolização prescreveu. Para Lacan (1955-1956/1988), dizer de uma foraclusão é falar da rejeição de um significante primordial, o que colocorá em xeque todo o sistema de significantes do sujeito.

É a partir do significante que o sujeito se reconhece como sendo algo ou não sendo, uma vez que esse significante significa algo para alguém. Aqui reside a importância do complexo de Édipo lacaniano como sendo algo pelo qual há - ou não - a introdução de um significante que afeta e estrutura o ser. Para que a realidade se apreenda da maneira que é na psicose, existe a condição de que o complexo de Édipo não tenha sido vivido. Se o campo que tomamos como Édipo na psicanálise não tiver uma estrutura simbólica, todo o sistema de significantes do sujeito será colocado em xeque. Sendo assim, não existe neurose sem Édipo e só há psicose porque algo no Édipo não se completou, fazendo com que a psicose se constitua numa falta do significante.

É na falta do significante primordial, o Nome-do-Pai, que, para Lacan, será estruturada a psicose. A não entrada do Nome-do-Pai na relação da criança com o Outro materno implica um não complemento do Édipo, fazendo com que o sujeito seja incluído fora da lei simbólica. 
Sendo assim, as relações que esse sujeito constrói serão na ausência desse mediador simbólico essencial.

Quando chamado a se apoiar na lei simbólica, o sujeito psicótico, segundo Quinet (2006a, p. 16), pode dar provas de sua estrutura, geralmente pelos distúrbios da linguagem, tratando-se, assim, "da alucinação do verbo, e não de um distúrbio ligado aos órgãos do sentido". Nesse momento, o Nome-do-Pai, que havia sido foracluído no simbólico, pode ser suprimido pela produção delirante. No caso de Schreber, estudado por Freud (1911/2010), quando chamado a uma posição fálica, a de ocupar a cadeira de presidente de um tribunal, ele inicia seus delírios. A invocação feita por Schreber ao Nome-do-Pai, que havia sido foracluído, faz seu retorno no real por meio de uma construção delirante - a de que procriaria uma nova raça de homens.

É nesse contexto que é desenvolvida uma concepção chave no ensino lacaniano das psicoses: a ideia de metáfora. Na metáfora existe a substituição de um significante por outro, e isso faz com que algo novo seja produzido, algo que é possível nomear. Na psicose existe uma forma muito específica de metáfora: a metáfora delirante. Esta é uma forma única que o psicótico possui de estabelecer ferramentas sem que seja pela via neurótica. A metáfora delirante, consequência da foraclusão do significante primordial, emerge para fazer suplência pela via do imaginário. É a partir da construção da metáfora delirante - a de que daria origem a uma nova raça de homens por meio de seu relacionamento com Deus, momento em que o delírio ocupa o lugar do Nome-do-Pai foracluído - que Schreber se estabiliza. Nesse momento, ele passa a ter acesso à significação por meio da metáfora delirante, e não por meio de uma significação fálica como ocorre na neurose (Lacan, 1955-1956/1988). Em nosso trabalho, fazemos a aposta de que o AT, ao caminhar no ambiente mais imediato das produções dos acompanhados, possa ser uma forma de possibilitar o surgimento dessa metáfora sem que ocupe uma posição de invasão para o sujeito psicótico - realidade que ele está sempre vivenciando.

Para Guerra (2010, p. 58), existem três condições que permitem a construção de uma metáfora delirante: "a) a presença da atividade delirante; b) o trabalho de localização delirante do gozo do Outro, através de uma operação de redução significante; c) o consentimento com a experiência de gozo aí nomeada". O delírio alcançaria, então, o status de metáfora para ter o efeito de uma organização. Se os profissionais tentam se valer de práticas protocolares de inclusão, práticas que não fazem sentido para o sujeito, corre-se o risco de um resultado que faz calar a produção dessa metáfora. Quando propomos o desenvolvimento dessa metáfora durante um AT, estamos falando de uma inclusão realizada a partir de uma amarração própria 
desse sujeito. E essa amarração, por vezes, é tão difícil de fazer entender justamente pelo fato de se valer de uma via delirante.

A proposta está em consonância com o que Lacan (1955-1956/1988) propõe como clínica da psicose. Nessa modalidade de clínica, Lacan enfatiza a posição do analista frente ao sujeito psicótico. Ele nos diz que o analista tem de se contentar em ser secretário do alienado. Nesse trabalho, quem produz é o próprio sujeito, caminhando no sentido de uma estabilização ao decorrer da organização desses conteúdos delirantes. Cabe ao secretário acompanhá-lo nessas produções, tomando o que esses sujeitos dizem ao pé da letra sem tentar se valer de interpretações. É a partir desse testemunho do sujeito que ele nos oferece uma amostra do que é sua experiência e do que se coloca como realidade para ele. Nesse sentido, a fala do sujeito será a referência enquanto ele narra ao psicanalista aquilo que dá testemunho como vindo do Outro. Assim, propomos aqui que o acompanhante possa ocupar essa posição de secretário, permitindo que o sujeito construa suas significações tão singulares rumo a uma estabilização, sem deixar, para isso, de caminhar pelo local onde posteriormente essas amarrações se farão presentes.

A exemplo do que acontece com Schreber, o sujeito possui uma relação muito única com a linguagem no momento em que manifesta seu delírio. Cabe a nós escutarmos esse delírio e essa organização única que o sujeito faz perante a linguagem, ajudando-o a dar um sentido para aquilo que somente ele pode testemunhar. Esse é o legado que Schreber nos deixa em suas memórias: o testemunho de uma construção que nos cabe, como analistas, o "direito de aceitar o testemunho do alienado em sua posição em relação à linguagem, e devemos tê-lo em conta na análise de conjunto das relações do sujeito com a linguagem" (Lacan, 1955-1956/1988, p. 238).

Lacan dá grande importância ao delírio enquanto solução psicótica para tentar fazer a suplência desse Nome-do-Pai que se encontra ausente. Para Guerra (2010), isso mostra, nesse momento da obra lacaniana a respeito das psicoses, que é dada em sua teoria uma enorme importância à base da estrutura da linguagem, do poder do significante e da primazia do simbólico, embora já seja evidenciado a função que o real desempenha nas estruturas clínicas.

Se, diante desse delírio cabe a nós a sustentação, ao invés de tentarmos fazer que o sujeito se cale, partimos da ideia de que podemos encontrar no AT um ponto de apoio para realizar esse trabalho. O acompanhante pode se situar, na nossa perspectiva, como um secretário desse sujeito oportunizando que ele venha a construir sua significação pela metáfora delirante ou por qualquer forma própria de amarração que lhe traga alguma estabilização enquanto caminha por onde ocorrem suas relações imediatas. Nesse aspecto, 
secretariar o acompanhado se afasta totalmente de incluí-lo por meio de seu silêncio, pois possibilita que ele faça laço e tenha inserção social por meio de algo que tenha sentido a partir de uma construção que lhe é própria.

\section{Conclusão}

Interessa-nos perceber, aqui, que, se o AT é fruto da Reforma Psiquiátrica, as transformações históricas que essa prática produz desde sua saída das instituições de cunho asilar até entrar no serviço da rede pública de saúde, são inseparáveis das características desse processo reformista. Vimos, então, que o AT nasce como uma prática que se pretende leiga devido à sua própria forma de surgimento dentro das Comunidades Terapêuticas. Naquele momento, a loucura começou a ser tomada como fruto da exclusão social, e não somente como uma consequência de algum desvio biológico. Consequentemente, há uma negação da singularidade da loucura em prol da aposta na dimensão social atrelada a ela. No entanto, a história do AT vem mudando com o desenvolvimento da própria história reformista: ele passa a ser feito em cargas horárias menores e a ter outro propósito para além da simples extensão do alcance psiquiátrico. Nessa perspectiva, hoje pensamos que o AT não é uma prática tão leiga assim e não porta mais os mesmos significantes desde seu surgimento. Uma das consequências disso, a mudança da nomenclatura de auxiliar psiquiátrico e amigo qualificado para acompanhante terapêutico, marca também a mudança de posição que esse profissional ocupa, pois o AT se afasta da condição de prática de caráter leigo. Dessa forma, temos a necessidade de mudança da posição desse acompanhante para que aconteça a escuta tão necessária desse sujeito na psicose e para que esse profissional possa oferecer de maneira mais efetiva a nova contingência que surge a partir da mudança de nomenclatura - a contingência terapêutica.

Embora o processo reformista esteja caminhando, e mesmo com muitos avanços no que diz respeito à atenção dada à loucura, ainda existem dificuldades ao se fazer avançar a saúde mental pública junto ao próprio avanço da construção de um Sistema Único de Saúde brasileiro. Devido a diversos fatores, como a resistência do setor hospitalar, há lentidão no processo de desinstitucionalização. Além disso, há dificuldades operacionais do Estado e das famílias, algumas falhas na articulação da Saúde Mental com a Atenção Básica e problemas na gestão e criação de políticas retrógadas que compactuam com o antigo sistema asilar, entre outros. 
O atual cenário da Saúde Mental apresenta muitos entraves. Existe uma desorganização do Estado que acaba culminando em decisões conservadoras no quadro das mais diversas políticas do SUS. Se isso já é um problema de maneira geral nas políticas públicas, no caso da Saúde Mental, segundo Tenório (2007), existe um entrave na organização devido às dificuldades intrínsecas da própria loucura. A Reforma Psiquiátrica é uma produção heterogênea que passa pelos mais diversos campos: o social, a política, as relações jurídicas, o cultural, etc. Nesse processo que vem se concretizando com a participação de diversos atores, não se deve esquecer, todavia, como argumenta o autor, do dispositivo clínico.

Esta separação entre clínica e política, na perspectiva de Palombini (2006, p. 120), precisa ser reinventada, "pois não há clínica que não seja ao mesmo tempo política, exercício de poderes. A questão é: qual política, qual exercício de poder, opera nossa clínica?”. A crítica de Palombini à suposta neutralidade existente no exercício profissional parte da aposta em que negar a subjetividade do sujeito é negar suas formas de pertencimento, recusando, consequentemente, a própria denúncia que o discurso da loucura traz de uma sociedade adoecedora e normatizante. Assim, se nós, profissionais, adentramos nesse enunciado da disciplinarização, corremos o risco de perder-junto ao próprio sujeito da psicose, a dimensão política que um dispositivo como o AT pode propiciar ao contexto da saúde mental ao oferecer uma escuta - uma escuta clínica.

A separação existente no discurso em torno da Reforma Psiquiátrica, que aparta a clínica do tratamento, pode ser prejudicial quando pensamos no sujeito presente na psicose, levando-o a uma cronificação nos serviços de saúde. Se o espaço do setting analítico tradicional carrega todo o peso ao colocar o sujeito como o centro produtor de uma fala, o que pode ocupar o lugar de invasão para a psicose, no AT a fala pode emergir com maior facilidade justamente por não ser convocada de maneira tão direta. Além disso, pelo fato de a escuta do AT ser in loco, torna-se possível acompanhar um delírio ou alguma outra forma de produção no momento e local em que ocorrem.

Quando entramos na discussão, então, sobre uma clínica psicanalítica que oriente o AT, na qual o acompanhante poderia ocupar esse lugar do secretário do psicótico, distanciando-se do gozo do sentido a qualquer custo e de uma inclusão no discurso normativo, ampliamos, também, esse debate para o modelo que os serviços de saúde mental vêm adotando para tratar a loucura. Assim, um AT orientado pela clínica psicanalítica das psicoses, que não deixa de lado a implicação social desse modo de estar no mundo, pode ser 
uma possibilidade de romper com essa dicotomia entre o que é social e o que é subjetivo, entre a política e a clínica no contexto dos serviços públicos da Reforma Psiquiátrica.

Embora a história reformista tenha origem no questionamento da clínica, ela não pode recalcar a discussão dessa escuta individualizada dada ao sujeito considerado louco, pois o retorno disso pode ter como resultado a não adesão do sujeito frente ao discurso das instituições ou mesmo sua cronificação nesses serviços. O AT, na nossa perspectiva de trabalho, pode ser colocado como uma prática de territorialização que vai contra esse desmonte da Rede de Atenção Psicossocial, que vem se reaproximando cada vez mais do modelo asilar, sem deixar de lado, para isso, a escuta clínica indispensável desse sujeito tão incomum e, por vezes, até delirante, que está presente na psicose.

\section{Referências}

Basaglia, F. (1985). A instituição negada. Rio de Janeiro: Graal.

Brasil. Ministério da Saúde. (2019). Nota técnica $n^{\circ}$ 11/2019, CGMAD/DAPES/SAS/MS. Brasília, DF: Autor. Recuperado de http://pbpd.org.br/wpcontent/uploads/2019/02/0656ad6e.pdf

Carrozzo, N. (1991). Apresentação. In Equipe de Acompanhantes Terapêuticos do Hospital Dia A Casa (Org.), A rua como espaço clínico: acompanhamento terapêutico (pp. 1113). São Paulo: Escuta.

Caiaffa, R. A. (1991). O Acompanhante Terapêutico e a rua: O social como constitutivo do acompanhamento. In Equipe de Acompanhantes Terapêuticos do Hospital Dia A Casa (Org.), A rua como espaço clínico: acompanhamento terapêutico (pp. 93-100). São Paulo: Escuta.

Castro, J. E. (2012). Psicose: O conceito e a clínica psicanalítica. In W. Melo et al. (Orgs.), Quando acabar o maluco sou eu (pp. 143-166). Rio de Janeiro: Espaço Artaud.

Dimenstein, M., \& Gruska, V. (2015). Reabilitação Psicossocial e Acompanhamento Terapêutico: Equacionando a reinserção em saúde mental. Psicologia Clinica, 27(1), 101-122. doi: 10.1590/0103-56652015000100006

Dunker, C. I. L. (2010). Psicanálise de orientação lacaniana. Mente e cérebro, 3, 7-41.

Dunker, C. I. L. (2013). A Psicose na criança: Tempo, linguagem e sujeito. São Paulo: Zagodoni.

Dunker, C. I. L., \& Kyrillos Neto, F. (2015). Psicanálise e saúde mental. Porto Alegre: Criação Humana. 
Fantin, A. D. (2017). O acompanhamento terapêutico (AT) como um dispositivo para a psicanálise no campo da saúde mental (Dissertação de mestrado). Universidade Federal de Santa Catarina, Centro de Filosofia e Ciências Humanas, Florianópolis, SC, Brasil. Recuperado de https://repositorio.ufsc.br/xmlui/handle/123456789/182722

Freud, S. (1996). As Neuropsicoses de Defesa. In S. Freud, Edição standard brasileira das obras psicológicas completas de Sigmund Freud (Vol. 3, pp. 49-65). Rio de Janeiro: Imago. (Obra original publicada em 1894)

Freud, S. (1996). Sobre a Psicoterapia. In S. Freud, Um caso de histeria: Três ensaios sobre a sexualidade e outros trabalhos: Edição Standard das Obras Psicológicas Completas de Sigmund Freud (Vol. 7, pp. 239-251). Rio de Janeiro: Imago. (Obra original publicada em 1905)

Freud, S. (2010). Observações psicanalíticas sobre um caso de paranoia (dementia paranoides) relatado em autobiografia (“O caso Schreber”). In S. Freud, Obras Completas (Vol. 10, pp. 9-80). São Paulo: Companhia das Letras. (Obra original publicada em 1911)

Freud, S. (2010). Uma dificuldade no caminho da psicanálise. In S. Freud, Obras completas (Vol. 14, pp. 179-187). São Paulo: Companhia das Letras. (Obra original publicada em 1917)

Freud, S. (2011). O eu e o Id. In S. Freud, Obras Completas (Vol. 16, pp. 13-74). São Paulo: Companhia das Letras. (Obra original publicada em 1923)

Freud, S. (2011a). Neurose e psicose. In S. Freud, Obras Completas (Vol. 16, pp. 176-184). São Paulo: Companhia das Letras. (Obra original publicada em 1924)

Freud, S. (2011b). A perda da realidade na neurose e na psicose. In S. Freud, Obras Completas (Vol. 16, pp. 214-222). São Paulo: Companhia das Letras. (Obra original publicada em 1924)

Furegato, A. R. F., \& Pitiá, A. C. A. (2009). O Acompanhamento Terapêutico (AT): Dispositivo de atenção psicossocial em saúde mental. Interface, 13(30), 67-77. doi: 10.1590/S1414-32832009000300007

Guerra, A. M. C. (2010). A psicose. Rio de Janeiro: Zahar.

Lacan, J. (1988). O seminário: livro 3: As psicoses (2a ed.). Rio de Janeiro: Jorge Zahar. (Obra original publicada em 1955-1956)

Lacan, J. (2003). Proposição de 9 de outubro de 1967 sobre o psicanalista da escola. In J. Lacan, Outros escritos (pp. 248-264). Rio de Janeiro: Jorge Zahar. (Obra original publicada em 1967) 
Marco, M. N. da C., \& Calais, S. L. (2012). Acompanhante Terapêutico: Caracterização da prática profissional na perspectiva da Análise do Comportamento. Revista Brasileira de Terapia Comportamental e Cognitiva, 14(3), 4-33. Recuperado de http://pepsic.bvsalud.org/scielo.php?script=sci_arttext\&pid=S151755452012000300002

Nogueira, A. B. (2009). O acompanhamento terapêutico e sua caracterização em Betim e Belo Horizonte. Psicologia em Revista, 15(2), 204-222. Recuperado de http://pepsic.bvsalud.org/scielo.php?script=sci_abstract\&pid=S1677$11682009000200013 \& \operatorname{lng}=$ pt\&nrm=iso

Palombini, A. de L. (2006). Acompanhamento terapêutico: Dispositivo clínico-político. Psychê, 10(18), 115-127. Recuperado de http://pepsic.bvsalud.org/scielo.php?script=sci_arttext\&pid=S141511382006000200012

Quinet, A. (2006a). Teoria e clínica da psicose. Rio de Janeiro: Forense Universitária.

Quinet, A. (2006b). Psicose e laço social: Esquizofrenia, paranoia, melancolia. Rio de Janeiro: Jorge Zahar.

Reis Neto, R. O., Oliveira, L. G. A., \& Pinto, A. C. T. (2011). Acompanhamento Terapêutico: História, Clínica e Saber. Psicologia: Ciência e Profissão, 31(1), 30-39. doi: 10.1590/S1414-98932011000100004

Ribeiro, A. M. (2009). A idéia de referência: O acompanhamento terapêutico como paradigma de trabalho em um serviço de saúde mental. Estudos de Psicologia, 14(1), 73-83. Recuperado de https://www.scielo.br/pdf/epsic/v14n1/a10v14n1.pdf

Rosa, M. D. (2004). A pesquisa psicanalítica dos fenômenos sociais e políticos: Metodologia e fundamentação teórica. Revista Mal-Estar e Subjetividade, 4(2), 329-348. Recuperado de http://pepsic.bvsalud.org/scielo.php?script=sci_arttext\&pid=S151861482004000200008

Santos, L. G. dos, Motta, J. M., \& Dutra, M. C. B. (2005). Acompanhamento terapêutico e clínica das psicoses. Revista Latino-americana de Psicopatologia Fundamental, 8(3), 497-514. doi: 10.1590/1415-47142005003007

Silva, A. S. T., \& Silva, R. N. (2006). A emergência do acompanhamento terapêutico e as políticas de saúde mental. Psicologia: Ciência e Profissão, 26(2), 210-222. doi: 10.1590/S1414-98932006000200005

Simanke, R. T. (1994). A formação da teoria freudiana das psicoses. Rio de Janeiro: Editora 34. 
Tenório F. (2007). Questões para uma atualização da agenda da Reforma Psiquiátrica. In M. C. V. Couto, \& R. G. Martinez (Orgs.), Saúde mental e saúde pública: Questões para a agenda da Reforma Psiquiátrica (pp. 11-28). Rio de Janeiro: Núcleo de Pesquisa em Políticas Públicas de Saúde Mental, Instituto de Psiquiatria, Universidade Federal do Rio de Janeiro.

\section{Endereço para correspondência}

\section{Mariana Vieira Morais}

Rua Miguel Roberto Sandim, 129, Dom Bosco, São João Del Rei - MG, Brasil. CEP 36301-018

Endereço eletrônico: mvieira519@gmail.com

\section{Fuad Kyrillos Neto}

Praça Dom Helvécio, 74 sala 2.15, Dom Bosco, São João Del Rei - MG, Brasil. CEP 36301-160

Endereço eletrônico: fuadneto@ufsj.edu.br

Recebido em: 14/06/2019

Reformulado em: 03/06/2020

Aceito em: 22/06/2020

\section{Notas}

* Mestre em Psicologia pelo programa de Pós-Graduação em Psicologia da Universidade Federal de São João del-Rei (UFSJ).

** Professor Associado do Departamento de Psicologia da Universidade Federal de São João del-Rei (UFSJ).

${ }^{1}$ Sobre esse aspecto veja a nota de esclarecimento da Coordenação Geral de Saúde Mental, Álcool e Outras Drogas de fevereiro de 2019 (Brasil, 2019)

Financiamento: Coordenação de Aperfeiçoamento de Pessoal de Nível Superior - CAPES.

Este artigo de revista Estudos e Pesquisas em Psicologia é licenciado sob uma Licença Creative Commons Atribuição-Não Comercial 3.0 Não Adaptada. 